\title{
Organic Aqua Regia: Discovery, Fundamentals, and Potential Applications
}

\author{
Wei Lin \\ School of Materials Science E Engineering, Georgia Institute of Technology \\ USA
}

\section{Introduction}

Recently, the author and his colleagues reported the discovery of a series of organic mixtures that dissolve various noble metals such as gold $(\mathrm{Au})$, silver $(\mathrm{Ag})$, and palladium (Pd) efficiently at room temperature (Lin et al., 2010). The author named these mixtures organicus liquor regius as the male counterpart of aqua regia (female) in Latin. For the readers to catch the term more easily, the author uses the term organic aqua regia (OAR) from here after. OAR is composed of thionyl chloride $\left(\mathrm{SOCl}_{2}\right)$ and an effective organic component. By varying the composition and reaction conditions, selective dissolution of noble metals was achieved. The discovery of OAR and their potential applications in many fields have attracted extensive attention (Yeston, 2010; NatureEditorial, 2010; Urquhart, 2010; Ritter, 2010). The chapter provides a brief description of our work on, and understanding of, OAR from three aspects: discovery, fundamental chemistry, and some of the potential applications that have been preliminarily demonstrated.

Section 2 describes how the author discovered OAR when studying chemical bonding of functionalized carbon nanotubes to an Au surface, and introduces some known properties (dissolution selectivity towards metals, and dissolution kinetics) of OAR, with a touch on some of the recipes of OAR that have been developed so far. A summary of the chemistry, strength, and issues of aqua regia - the ever most powerful solution to dissolve noble metals in history, and a tabulated comparison between OAR and aqua regia is presented. When one thinks about "dissolution" of sodium chloride in water, the word-dissolve-might sound somewhat misleading for describing the oxidation process of metallic Au by the reagent, the accompanying complexation, and the solvation processes in the solution; however, the author keeps using the terms such as "dissolve", "dissolution", and "solubility" in the chapter following the conventional description of oxidative dissolution of metals in hydrometallurgy. The author believes the readers have no problem distinguishing the dissolution of metals with that of salts/sugar.

A significant portion of the chapter is then devoted in Section 3 to some fundamental chemistry of OAR, with the focus on the Au-SOCl 2 -pyridine system. $\mathrm{SOCl}_{2}$ and its mixture with pyridine (py) have been widely used in organic chemistry for decades; however, the chemistry of $\mathrm{SOCl}_{2}$-py is still now well understood. Our rigorous study on $\mathrm{SOCl}_{2}$-py has provided some new fundamental understanding of the mixture. Also discussed is the 
possible mechanism for the $\mathrm{Au}$ dissolution in the $\mathrm{SOCl}_{2}$-py mixture. A surface reaction mechanism is proposed. Section 4 discusses some potential applications of OAR such as etching of metals in microelectronics industry, and recovery of noble metals from catalysis industry and consumer products, etc. Our recent progress is presented.

\section{Discovery of OAR}

As many discoveries were, the discovery of OAR was accidental. In 2007, the author was involved in developing a chemical bonding process to anchor in situ functionalized vertically aligned carbon nanotubes to a modified Au surface. The basic chemistry was to assemble a thin layer of 4-mercaptobenzoic acid molecules on the Au surface, and then form the bonding between the functional groups (e.g., hydroxyl groups) on the carbon nanotubes and the acid groups of the 4-mercaptobenzoic acid molecules via esterification (Fig. 1). However, there were some fundamental challenges to such a bonding process. First, solidsolid reaction at the interface was very unlikely to occur given the low functionalization degree of the carbon nanotubes and the irregular surface of the carbon nanotubes (at that time very few people talked about the irregular surface of the macroscopically well-aligned carbon nanotubes). Second, a wet chemical reaction at the interface was preferred, e.g., a catalyzed esterification reaction in an aqueous solution. However, the wet chemical process-if not controlled well-would damage the vertical alignment of the carbon nanotubes (at that time very few people revealed the truth that a vertically aligned carbon nanotubes array/bundle could easily collapse in wettable liquids). Third, direct esterificaiton of benzoic acid with alcohol had been known to be very inefficient (Vulakh et al., 1975; Zuffanti, 1948), and therefore, kinetically unlikely at the interface. To address these issues, the benzoic acid group was first transformed to the benzoic acid chloride group by the reaction with $\mathrm{SOCl}_{2}$ in the presence of a certain concentration of py as the catalyst. A dilute solution of $\mathrm{SOCl}_{2}(5 \sim 10 \mathrm{ppm})$ in acetonitrile $\left(\mathrm{CH}_{3} \mathrm{CN}\right)$ with a trace amount of py (py: $\mathrm{SOCl}_{2}=1: 2$ in mole) was used (illustrated in Fig. 2).

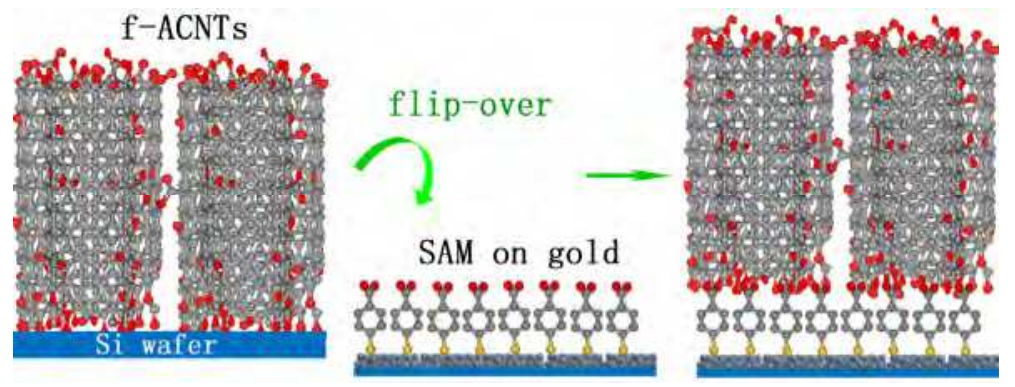

Fig. 1. Illustration of the idea of chemical bonding of in situ functionalized vertically aligned carbon nanotubes (f-ACNTs) to a functionalized Au surface. The red dots on the f-ACNTs represent the functional groups such as epoxide and hydroxyl groups (Lin et al., 2008).

When the author was studying the functionalization (esterification) reaction, something unexpected but interesting happened one day: in the presence of py, a relatively high concentration of $\mathrm{SOCl}_{2}$ resulted in efficient dissolution of $\mathrm{Au}$ in the organic solution at room temperature. Soon after the author confirmed that $\mathrm{Au}$ was not soluble at all in either $\mathrm{SOCl}_{2}$ 
or py, or the above-mentioned very dilute $\mathrm{SOCl}_{2}-\mathrm{py} / \mathrm{CH}_{3} \mathrm{CN}$ solution, the author realized the similarity between the organic mixtures and aqua regia. Aqua regia has been used for centuries as a powerful etchant to dissolve noble metals. The beauty of aqua regia is that the simple 1:3 mixture of concentrated nitric and hydrochloric acids can dissolve various noble metals while the noble metals are not soluble in either of the acids. The organic mixtures have exactly the same beauty with aqua regia: simple mixtures; therefore, the author names the mixtures organic aqua regia (OAR). My curiosity pushed me to try other materials in the $\mathrm{SOCl}_{2}$-py mixture (with and without $\mathrm{CH}_{3} \mathrm{CN}$ ); qualitative results are listed in Table 1.

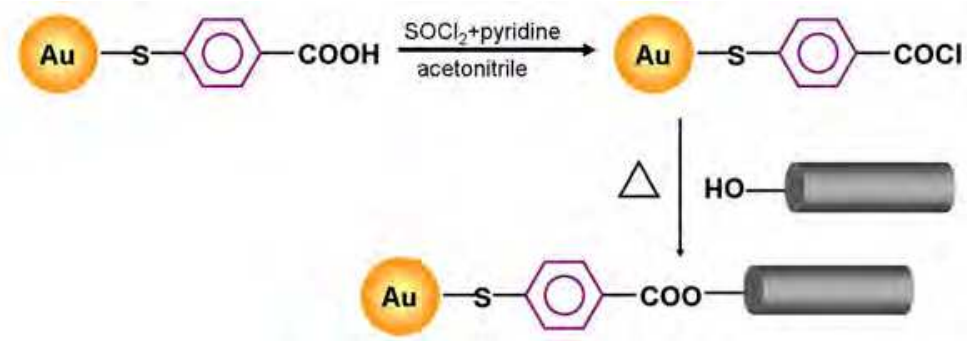

Fig. 2. Esterification process at the interface between the f-ACNTs and the modified Au surface.

\begin{tabular}{|c|c|}
\hline material & dissolution $(\mathrm{Y} / \mathrm{N})$ \\
\hline silver & $\mathrm{Y}$ \\
\hline gold & $\mathrm{Y}$ \\
\hline platinum & $\mathrm{N}$ \\
\hline palladium & $\mathrm{Y}$ \\
\hline copper & $\mathrm{Y}$ \\
\hline iron & $\mathrm{Y}$ \\
\hline nickel & $\mathrm{Y}$ \\
\hline titanium & $\mathrm{N}$ \\
\hline tungsten & $\mathrm{N}$ \\
\hline tantalum & $\mathrm{N}$ \\
\hline chromium & $\mathrm{N}$ \\
\hline tin & $\mathrm{Y}$ \\
\hline indium & $\mathrm{Y}$ \\
\hline Teflon & $\mathrm{N}$ \\
\hline silicon & $\mathrm{N}$ \\
\hline silicon oxide & $\mathrm{N}$ \\
\hline
\end{tabular}

Table 1. Qualitative results of dissolution of various materials in the $\mathrm{SOCl}_{2}$-py mixture.

The discovery promises more than the beauty and simplicity. The distinct difference between OAR and aqua regia is that OAR are non-aqueous, which is important. Compared with inorganic chemistry, organic chemistry provides a precise control over chemical reactivity. The ability to engineer organic reactions would probably enable selective dissolution of noble metals. A few non-aqueous solutions for dissolving noble metals have been preliminarily investigated (Senanayake, 2008; Raisanen et al., 2007; Mortier et al., 2005; 
Cau et al., 2003; Nakao, 1992), however, with relatively unsatisfactory solubility, selectivity, efficiency, stability, or/and simplicity. Soon after the discovery of OAR, the author and his colleagues started to work on the formulation of OAR for selective dissolution of noble metals. Some preliminary results are presented here. Fig. 3 shows the kinetic results of the dissolution of noble metals in the mixture of $\mathrm{SOCl}_{2}$ and py with a volumetric ratio of 3:1. The mixture dissolves $\mathrm{Au}$ at a rate of $0.3 \mathrm{~mol} \mathrm{~m}^{-2} \mathrm{~h}^{-1}$ at room temperature, which is faster than Au dissolution in conventional cyanide leaching agents $\left(<0.004 \mathrm{~mol} \mathrm{~m}^{-2} \mathrm{~h}^{-1}\right)$ and iodide etchants (<0.16 mol m$\left.{ }^{-2} \mathrm{~h}^{-1}\right)$ (Senanayake, 2008; Qi \& Hiskey, 1991). Ag and Pd can also be dissolved at high dissolution rates $\left(0.8 \mathrm{~mol} \mathrm{~m}^{-2} \mathrm{~h}^{-1}\right.$ and $0.5 \mathrm{~mol} \mathrm{~m}^{-2} \mathrm{~h}^{-1}$, respectively); platinum (Pt) is completely inert. In a comparison, Fig. 4 shows that a $\mathrm{SOCl}_{2}-\mathrm{DMF}\left(\mathrm{N}^{\prime} \mathrm{N}^{\prime}-\right.$ dimethylformamide) mixture dissolves $\mathrm{Au}$ at a rate of $0.3 \mathrm{~mol} \mathrm{~m}^{-2} \mathrm{~h}^{-1}$; neither $\mathrm{Pd}$ nor $\mathrm{Pt}$ is apparently dissolved.

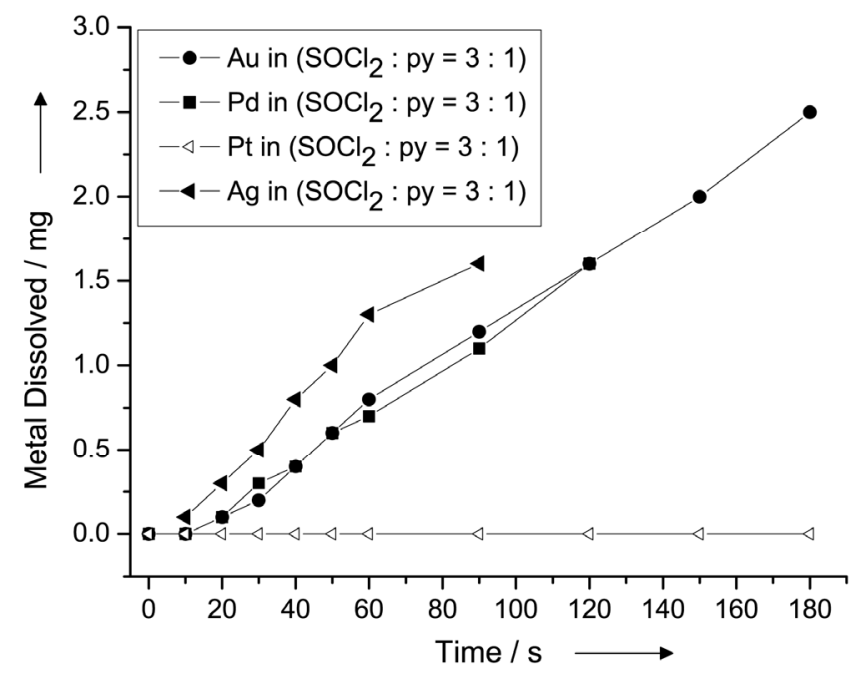

Fig. 3. Kinetic studies of the dissolution of $\mathrm{Au}, \mathrm{Pd}, \mathrm{Ag}$, and $\mathrm{Pt}$ in a 3:1 $\mathrm{SOCl}_{2}$-py mixture.

Such dissolution selectivity may find many important applications such as recovery of noble metals. The global energy crisis demands for green energy technologies, which undoubtedly requires increased noble metal resources. However, on the earth, noble metals are scarce. The ability to recover high-purity noble metals via recovery processes will be paramount to the sustainable development of human being. Among the noble metals, $\mathrm{Pt}$ is most widely used as a catalyst in many green technologies, in particular, proton-exchange membrane fuel cell. $\mathrm{Pt}$ recovery, however, has long been a challenging issue. Catalyst product stream starts with high-purity $\mathrm{Pt}$, and combines $\mathrm{Pt}$ with other noble metal elements for various purposes. The conventional $\mathrm{Pt}$ recovery technologies are complicated, mainly relying on the dissolution of $\mathrm{Pt}$ in strong inorganic acids (aqua regia) and subsequent precipitation of the dissolved Pt from the solution (Awadalla et al., 1992; Edwards \& Nattrass, 1978; Lakewood \& Arvada, 1977). However, aqua regia dissolves all the metals at the same time and cannot separate them out. It ends up with low-purity Pt which doesn't go back to the product stream directly; it has to be refined, but refinery is costly. Moreover, auqa regia is notoriously dangerous to work with; it is 
not recyclable; it is environmentally hazardous. In comparison, OAR may provide a route to improve the recycling quality and efficiency of $\mathrm{Pt}$ by a selective dissolution process. The selective dissolution process removes the impurity noble metals ( $\mathrm{Ag}, \mathrm{Au}$, and $\mathrm{Pd}$, etc.) before the final dissolution/separation of Pt. Schematic illustration of the recovery process using OAR is shown in Fig. 5; the preliminary results will be discussed in Section 4. Besides, OAR is recyclable (simply by distillation), and dilute OAR are relatively safe and easy to handle. A comparison between aqua regia and OAR is listed in Table 2.

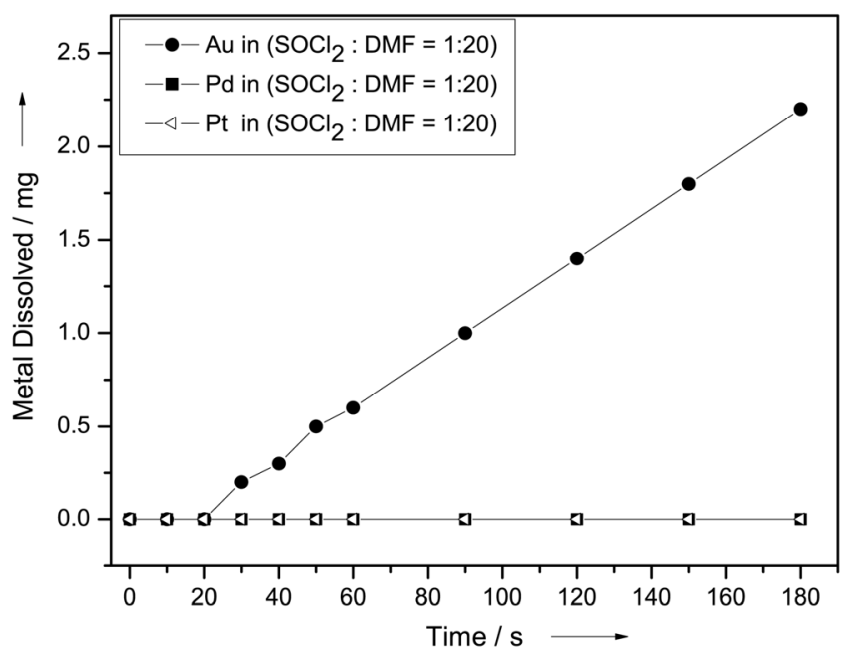

Fig. 4. Kinetic studies of the dissolution of $\mathrm{Au}, \mathrm{Pd}$, and $\mathrm{Pt}$, respectively, in a 1:20 $\mathrm{SOCl}_{2}-\mathrm{DMF}$ mixture.

So far, the chemicals that have been found to work as the effective basic components to compose OAR with $\mathrm{SOCl}_{2}$ for dissolving $\mathrm{Au}$ include, but are by no means limited to, the following chemicals and their derivatives: pyrrole, pyrrolidine, pyrrolidone, isoxazole, isothiazole, pyrazole, imidazole, thiazole, oxazole, pyrazolone, bipyrazole, pyridine, pyridazine, pyrimidine, pyrazine, triazine, indole, quinoline, purine, pteridine, phthalocyanine, N, N'-dicyclohexylcarbodiimide, DMF, N, $\mathrm{N}^{\prime}$-dimethylbenzylamine, dodecyltrimethylammonium bromide, tri-p-tolyl-phosphine, etc. Effective dissolution of $\mathrm{Au}$ in a mixture of $\mathrm{SOCl}_{2}$ with any of the following chemicals has not been observed: maleimide, azobisisobutyronitrile, aniline, polyaniline, phenanthroline, methylbenzyl cyanide, 2-acetyl-1-methylpyrrole, benzyltriethylammonium tetrafluoroborate.

\section{Fundamental chemistry of the $\mathrm{SOCl}_{2}-\mathrm{py}$ mixture and the Au-SOCl $2-\mathrm{py}$ system}

One key feature that all the aforementioned organic candidates have in common is that they more or less have charge-transfer interactions with $\mathrm{SOCl}_{2}$ (Schenk \& R. Steudel, 1963; Korshak et al., 1971), where the sulfur in $\mathrm{SOCl}_{2}$ is an electron acceptor, and the nitrogen (or phosphor) an electron donor. Let us focus on the $\mathrm{Au}-\mathrm{SOCl}_{2}$-py system. 


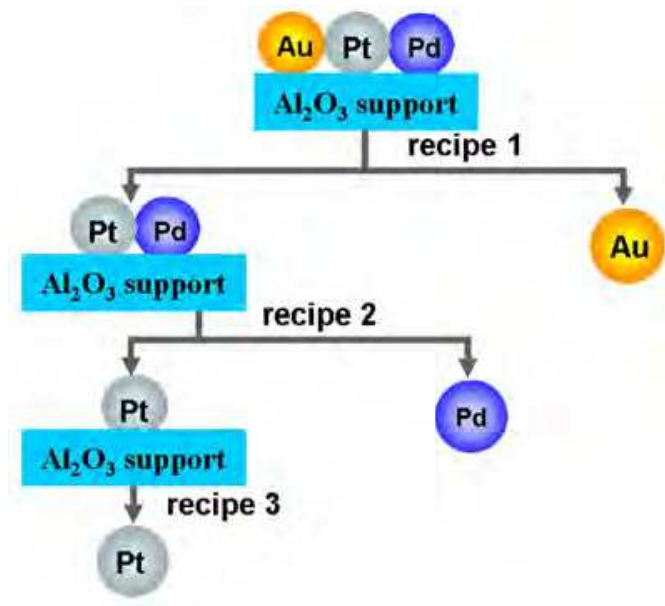

Fig. 5. Schematic illustration of the recovery of high-purity Pt on the basis of the dissolution selectivity of OAR toward noble metals.

\begin{tabular}{|c|c|c|}
\hline & aqua regia & OAR \\
\hline composition & $\begin{array}{c}\text { nitric acid }+ \text { hydrochloric } \\
\text { acid }\end{array}$ & innumerous \\
\hline concentration & concentrated & customized \\
\hline safety & explosive and corrosive & corrosive \\
\hline recyclable & $\mathrm{N}$ & $\mathrm{Y}$ \\
\hline dissolution of noble metals & indiscriminate & selective \\
\hline
\end{tabular}

Table 2. A comparison between aqua regia and OAR

\section{1 $\mathrm{SOCl}_{2}$-py mixture}

Py (structure a in Fig. 6) has been known for long to be able to catalyze the synthesis of acyl chlorides $(\mathrm{RCOCl})$ by the reaction between organic acids and $\mathrm{SOCl}_{2}$ (Cade \& Gerrard, 1953; Gerrard \& Thrush, 1953; Higashi et al., 1986; Human \& Mills, 1946). So has DMF. From a bromination reaction of py in the presence of $\mathrm{SOCl}_{2}$, Garcia et al. proposed a reaction between py and $\mathrm{SOCl}_{2}$ involving the probable equilibrium among 1-(chlorosulfinyl)-pyridinium chloride (structure b in Fig. 6), 1-(chlorosulfinyl)-4-chloro-4-hydropyridine (structure c in Fig. 6), and further reaction products (Garcia et al., 1960). Such proposed reaction equilibrium was thought by Higashi et al. to be the mechanism for esterification reactions between carboxylic acids and $\mathrm{SOCl}_{2}$ using py as the catalyst (Higashi et al., 1986). However, no systematic spectroscopic study on the $\mathrm{SOCl}_{2}$-py mixture has been reported so far. It is a fact that there is a strong interaction between py and $\mathrm{SOCl}_{2}$, which can be seen by the "white fog" formed when either of them is added to the other at room temperature. In fact, immediate yellowing of the solution is observed when py and $\mathrm{SOCl}_{2}$ are mixed fast at room temperature. Such a strong interaction is due to the formation of a charge-transfer complex between py and $\mathrm{SOCl}_{2}$ (partial transfer of the electron density on the nitrogen to the sulphur). The charge transfer (structure shown in Fig. 7), in general, weakens the bonds within the acceptor molecule (R. Steudel \& Y. 
Steudel, 2007), which accounts for the observed redshifts of both the asymmetric (from 446 to $427 \sim 426 \mathrm{~cm}^{-1}$ ) and the symmetric (from 497 to $494 \sim 474 \mathrm{~cm}^{-1}$ depending on the ratio of $\mathrm{SOCl}_{2}$ to py) $\mathrm{Cl}-\mathrm{S}-\mathrm{Cl}$ stretching in the Raman spectra of the $\mathrm{SOCl}_{2}$-py mixtures (Fig. 8). $\mathrm{SOCl}_{2}$-py is observed directly in the mass spectrum of the $\mathrm{SOCl}_{2}$-py mixture (Lin et al., 2010). Nuclear magnetic resonance (NMR) spectra of the $\mathrm{SOCl}_{2}$-py mixture are shown in Fig. 9. Table 3 summarizes the chemical shifts. We see the deshielding (low-field chemical shifts) of ${ }^{14} \mathrm{~N}$ (ca, 5 ppm), ${ }^{13} \mathrm{C}$ (ca, 1.35 and 2.42 ppm for $\mathrm{C}-3$ and $\mathrm{C}-4$, respectively), and ${ }^{1} \mathrm{H}$ (ca, $0.35,0.49$ and 0.50 ppm for H-2, H-3 and H-4, respectively), and shielding (high-field chemical shift) of C-2 (ca, $1.77 \mathrm{ppm})$ relative to pure py. These chemical shifts are attributed to the charge-transfer interaction (Ricca \& Severini, 1988). We also observe shifts and intensity changes of py-related vibration peaks in the FTIR of the $\mathrm{SOCl}_{2}$-py mixture relative to pure py and $\mathrm{SOCl}_{2}$ (Fig. 10). Such shifts are in agreement with our simulation results (Lin et al., 2010).

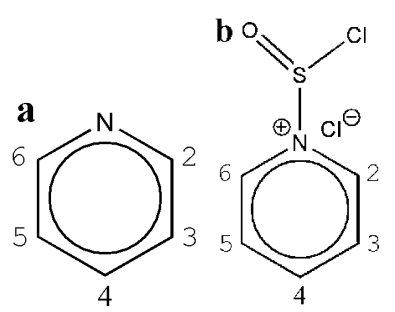<smiles>O=S(Cl)N1C=CC(Cl)C=C1</smiles>

Fig. 6. Structures of py (a), 1-(chlorosulfinyl)-pyridinium chloride (b), and 1-(chlorosulfinyl)4-chloro-4-hydropyridine (c). The numbering of atoms is applied to the NMR analysis.

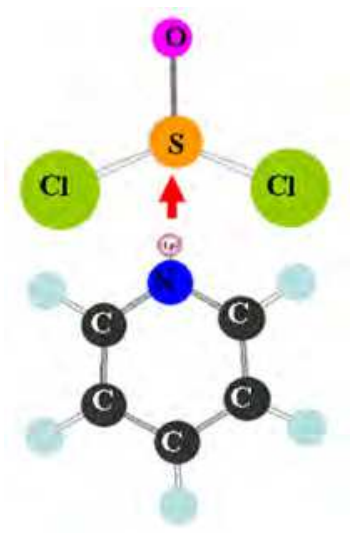

Fig. 7. The molecular illustration of the $\mathrm{SOCl}_{2}$-py charge-transfer complex.

In the Raman and the FTIR spectra of the $\mathrm{SOCl}_{2}$-py mixtures, almost all the vibration modes of pure py and pure $\mathrm{SOCl}_{2}$ remain unchanged. This indicates that the parent molecules, although perturbed by the charge-transfer interaction, maintain their basic structural integrity, and that the dominating product is a molecular adduct rather than a rearrangement, elimination or dissociated product. Neither 1-(chlorosulfinyl)-pyridinium chloride nor 1-(chlorosulfinyl)-4-chloro-4-hydropyridine is identified in the NMR spectra or 
FTIR spectra (Cade, \& Gerrard, 1953; Higashi et al., 1986; Human \& Mills, 1946; Garcia et al., 1960). However, the experimental data of electrical conductivity measurement of the mixtures suggest the presence of mobile ions due to the dissociation. Therefore, 1(chlorosulfinyl)-pyridinium chloride, though being a weak electrolyte in $\mathrm{SOCl}_{2}$ (Fig. 11), exists as the dissociated form of the $\mathrm{SOCl}_{2}$ - py adduct in the solutions. Geometry optimization results show that: $\mathrm{SOCl}_{2}$-py adduct (non-dissociated) is energetically more favorable than 1-(chlorosulfinyl)-pyridinium chloride, the dissociated form of the adduct, the latter being $16.8 \mathrm{kcal} \mathrm{mol}^{-1}$ higher in energy than the former (the energy difference will be lowered when put into a condense phase, depending on the dielectric constant of the solvent). This helps explain why the adduct is a weak electrolyte in $\mathrm{SOCl}_{2}$.

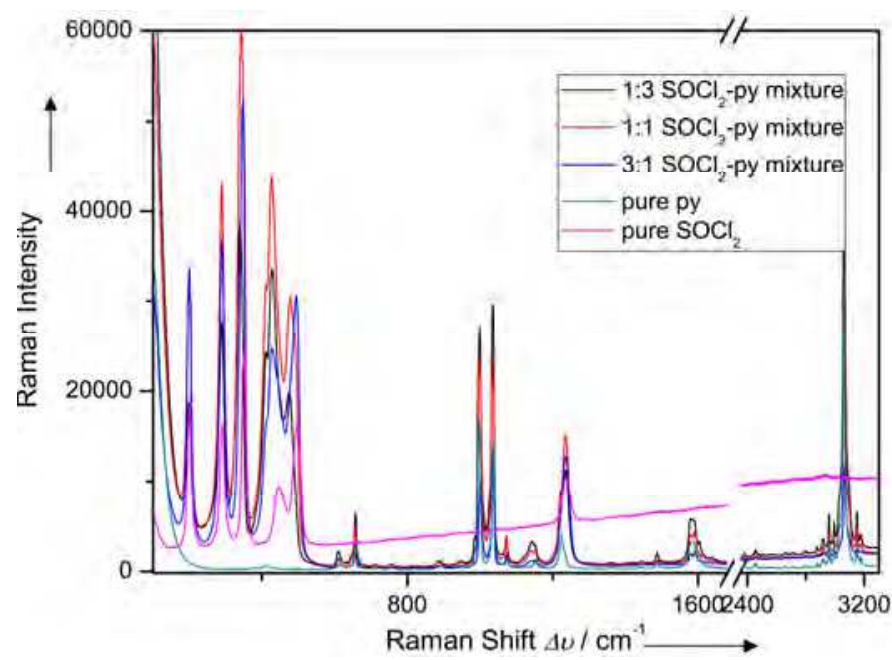

Fig. 8. 532-nm-laser-wavelength Raman spectra of $\mathrm{py}, \mathrm{SOCl}_{2}$, and their mixtures with varied ratios.

\subsection{Au dissolution in the $\mathrm{SOCl}_{2}$-py mixture}

It has been confirmed that the valence state of gold after the dissolution is $\mathrm{Au}(\mathrm{III})$, in the form of $\left[\mathrm{AuCl}_{4}\right]^{-}$(Lin et al., 2010). The Raman spectrum in Fig. 12 shows the $\left[\mathrm{AuCl}_{4}\right]^{-}$ structure. From the view of thermodynamics, dissolution of noble metals usually requires a strong oxidant, and simultaneously ligands that coordinate with the noble metal ion to reduce the redox potential of the metal in the solution. Obviously, $\mathrm{Cl}^{-}$is the ligand in this case. Although even chemists may not be aware of the strong oxidizing ability of $\mathrm{SOCl}_{2}$, it should be noted that $\mathrm{Au}(\mathrm{I}) \rightarrow \mathrm{Au}(\amalg)$ oxidation by $\mathrm{SOCl}_{2}$ has been demonstrated under certain conditions (Schmidbaur \& Jandik, 1983; Bovio et al., 1993). $\mathrm{SOCl}_{2}$ oxidizes $\mathrm{Cu}$ and $\mathrm{Ag}$ readily at room temperature. Thus, $\mathrm{SOCl}_{2}$ is a strong oxidant, and it can be the oxidant in our case. However, Au cannot be oxidized by $\mathrm{SOCl}_{2}$ alone. No weight loss was detected of an $\mathrm{Au}$ film after it was immersed in $\mathrm{SOCl}_{2}$ at room temperature or even at $70{ }^{\circ} \mathrm{C}$ (refluxing) for 1 week. Purging oxygen into the $\mathrm{SOCl}_{2}$ bath doesn't oxidize $\mathrm{Au}$, either. Py, undoubtedly, plays a very important role in the oxidative dissolution process. We believe that the chargetransfer interaction activates $\mathrm{SOCl}_{2}$ to oxidize Au. 


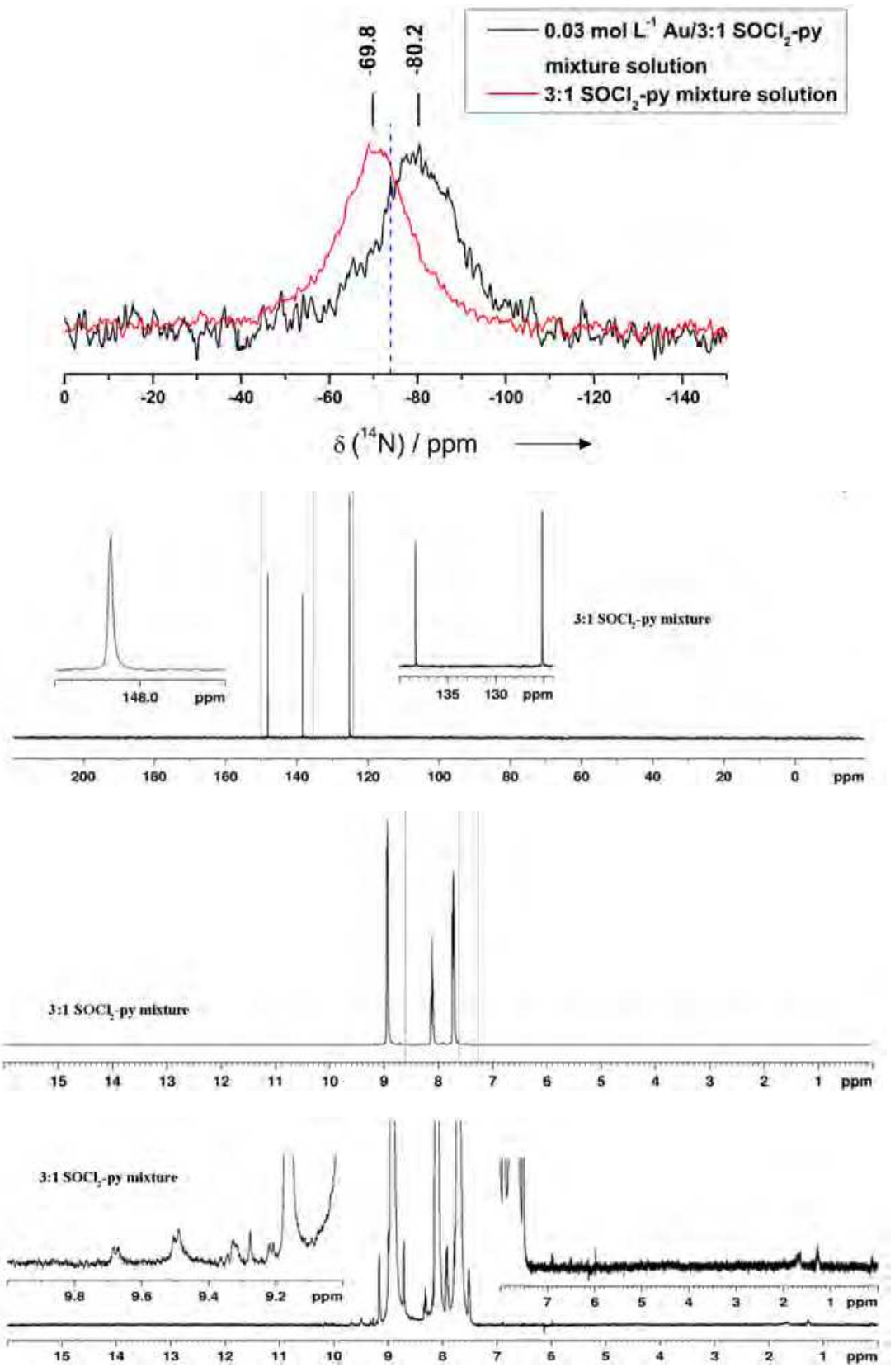

Fig. 9. ${ }^{14} \mathrm{~N},{ }^{13} \mathrm{C}$, and ${ }^{1} \mathrm{H}$ NMR spectra of a 3:1 $\mathrm{SOCl}_{2}$-py mixture and its Au solution. The dashed lines represent the chemical shifts of $\delta=74(14 \mathrm{~N}), 8.59(\mathrm{H}-2$ and H-6), $7.23(\mathrm{H}-3$ and H-5), 7.62 (H-4), 149.94 (C-2 and C-6), 123.75 (C-3 and C-5) and 135.89 (C-4) ppm for pure py. The insets are the magnified regions of the spectra. 


\begin{tabular}{|c|c|}
\hline$\delta\left({ }^{1} \mathrm{H}\right)$ of 3:1 $\mathrm{SOCl}_{2}$-py mixture & $\delta\left({ }^{13} \mathrm{C}\right)$ of 3:1 $\mathrm{SOCl}_{2}$-py mixture \\
\hline $9.68(\mathrm{~d}, \mathrm{~J}=6.0)$ & $148.17(2.9)$ \\
\hline $9.50(\mathrm{~d}, \mathrm{~J}=5.8)$ & $138.32(2.3)$ \\
\hline $9.28(\mathrm{~s})$ & $125.15(2.0)$ \\
\hline $9.21(\mathrm{~d}, \mathrm{~J}=4.6)$ & \\
\hline $9.17(\mathrm{~d}, \mathrm{~J}=4.1)$ & \\
\hline $\mathbf{8 . 9 4}(\mathrm{d}, \mathrm{J}=\mathbf{4 . 5})$ & \\
\hline $8.75(\mathrm{~d}, \mathrm{~J}=4.2)$ & \\
\hline $\mathbf{8 . 1 2}(\mathbf{t}, \mathbf{J}=\mathbf{7 . 8})$ & \\
\hline $7.72(\mathrm{t}, \mathrm{J}=\mathbf{6 . 6})$ & \\
\hline $7.52(\mathrm{t}, \mathrm{J}=6.1)$ & \\
\hline $1.56(\mathrm{~s})$ & \\
\hline $1.18(\mathrm{~s})$ & \\
\hline
\end{tabular}

Table 3. Summary of solution NMR data. Left column: " $s$ ", " $\mathrm{d}$ " and " $\mathrm{t}$ " in the brackets represent "singlet", "doublet" and "triplet". The values in bold are the major chemical shifts. Right column: the values in the brackets are the half-height line-width $\left(v_{1 / 2}\right)$.

One drawback of thermodynamics is that it doesn't tell the reaction kinetics (in most cases, thermodynamics doesn't relate to kinetics). For example, the coordinative oxidation mechanism may not be able to explain why the dissolution rate of $\mathrm{Au}$ is strongly dependent on the recipe of the OAR, especially the organic component such as py, DMF, pyrrolidine, pyrrolidone, isoxazole, isothiazole, pyrazole, imidazole, etc. The reaction rate in different OAR recipes can be orders of magnitude different! Moreover, $\mathrm{Pd}$ and $\mathrm{Pt}$ are less noble than $\mathrm{Au}$, but are not oxidatively dissolved in many recipes of OAR. The fundamental view of the dissolution reaction, therefore, points toward an interfacial reaction mechanism as shown in Fig. 13. The proposed mechanism involves two important roles by the organic component, say py, in two major steps. First, py coordinates to the Au surface by putting the non-bonding electrons in py (according to molecular orbital theory) to the accessible and symmetry allowed atomic orbital of the metal element. As such, the work function of the noble metal is effectively reduced (this has been known for quite a while), and therefore, the surface noble metal atoms are more liable to oxidation by the oxidant, i.e., activated $\mathrm{SOCl}_{2}$. Second, py forms the chargetransfer complex with $\mathrm{SOCl}_{2}$ to activate the oxidant; upon capture of the electrons from $\mathrm{Au}, \mathrm{Cl}$ $\mathrm{S}-\mathrm{Cl}$ dissociates to generate the $\mathrm{Cl}^{-}$as the ligand. The author proposes that the surface coordination between $\mathrm{Au}$ and py, and later on the desorption of py after the electron transfer from $\mathrm{Au}$ to sulfur, determine the reaction rate. As such, the electron structure and physical properties of the organic component determine its interactions with $\mathrm{SOCl}_{2}$ and the gold surface, and consequently, determine the dissolution kinetics. The two sets of experiment below may shed some light on the interfacial reaction mechanism.

In one set of experiment, $\mathrm{Au}$ is put in $\mathrm{SOCl}_{2}$; then a small amount of water is added to generate free $\mathrm{Cl}^{-}$(caution: $\mathrm{SOCl}_{2}$ reacts with water rigorously). The presence of $\mathrm{Cl}^{-}$can be very easily picked up by electrical conductivity measurement. Then anhydrous py is added as usual. It is found that the dissolution rate of $\mathrm{Au}$ is reduced. When DMF is used rather than py, the dissolution sometimes doesn't occur. For comparison, in the other set of experiment, $\mathrm{Au}$ is put in the anhydrous py before adding the $\mathrm{SOCl}_{2}$ (a small amount of water is added to the $\mathrm{SOCl}_{2}$ 


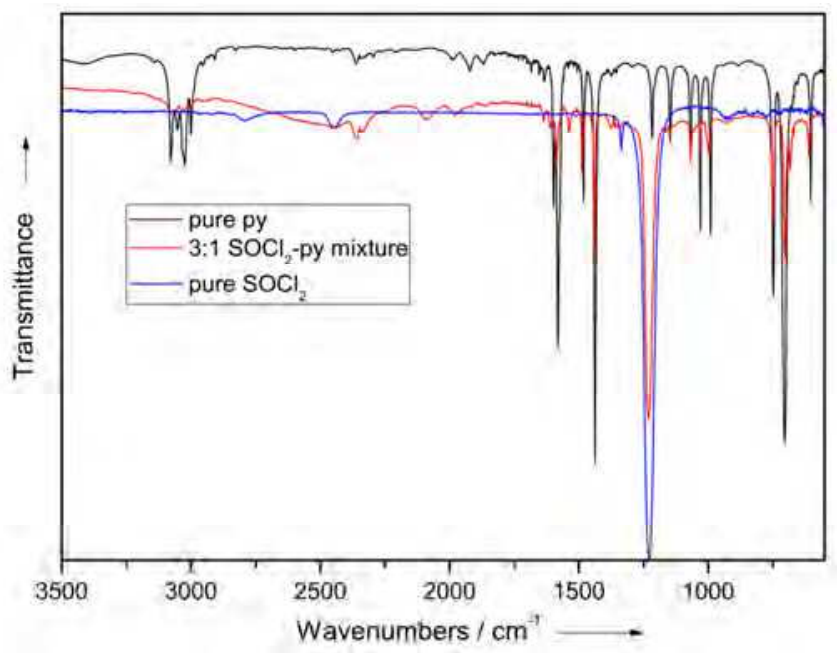

Fig. 10. FTIR spectra of py, $\mathrm{SOCl}_{2}$, and their mixture.

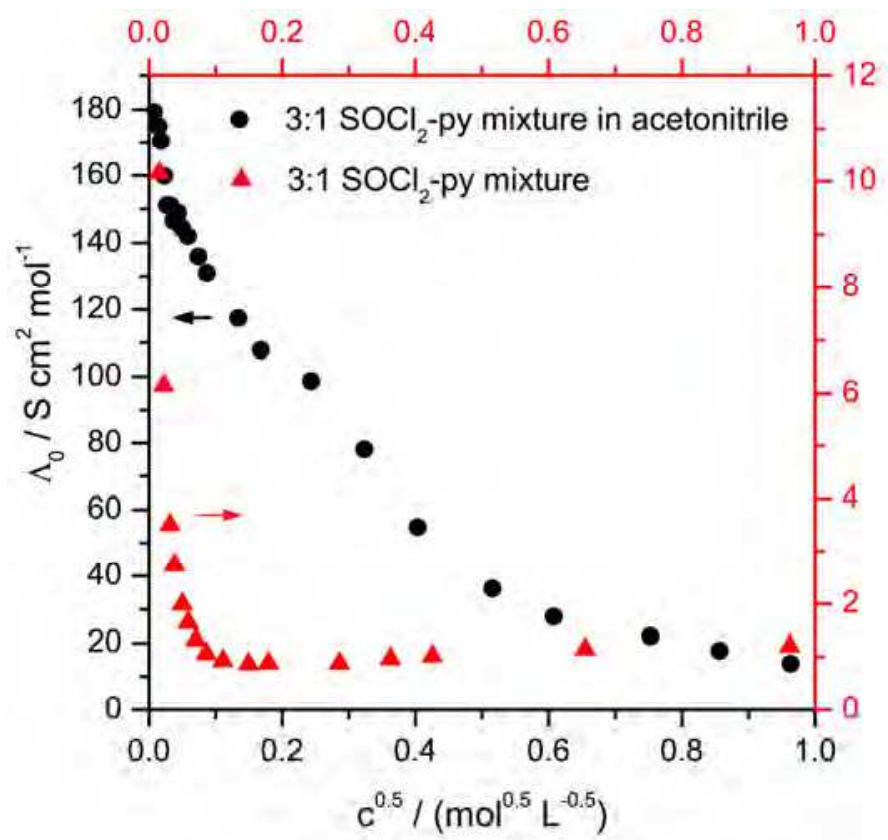

Fig. 11. Conductivity measurement results (III): $\Lambda-c^{0.5}$ plot, where $\mathrm{c}$ is the concentration of $\mathrm{SOCl}_{2} \cdot$ py adduct in the solution, and $\Lambda$ the molar conductivity of the electrolyte. It is clear that $\mathrm{SOCl}_{2} \cdot$ py is a weak electrolyte in $\mathrm{SOCl}_{2}$ matrix; its dissociation degree increases in acetonitirle. This is in line with our prediction because $\mathrm{SOCl}_{2}$ has a lower dielectric constant (9.3) and higher viscosity $(0.6 \mathrm{cP})$ than $\mathrm{CH}_{3} \mathrm{CN}$ (36.2 and $0.3442 \mathrm{cP}$, respectively) (Geary, 1971; Harkness \& Daggett Jr., 1965). 
first). No distinct change in the dissolution rate of $\mathrm{Au}$ is found. When DMF is used rather than py, the dissolution rate is somewhat reduced. From the experiments, the author postulates that when the coordination between $\mathrm{Au}$ and py is interrupted by $\mathrm{Cl}^{-}\left(\mathrm{Cl}^{-}\right.$adsorption on metal surfaces is notorious in electrochemistry), the reaction rate is greatly affected. Py-Au coordination is relatively less affected by the $\mathrm{Cl}^{-}$than DMF-Au coordination.

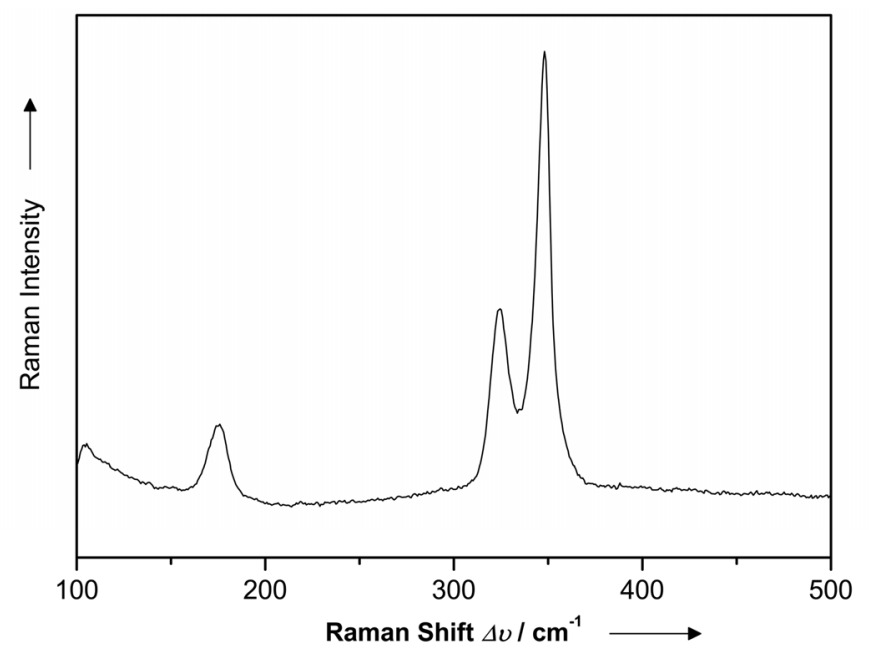

Fig. 12. Raman spectrum of a vapor-etched $\mathrm{Au} / \mathrm{Si}$ surface. Vibrations attributed to $\left[\mathrm{AuCl}_{4}\right]^{-}$ structure are observed at 170,324 , and $348 \mathrm{~cm}^{-1}$.

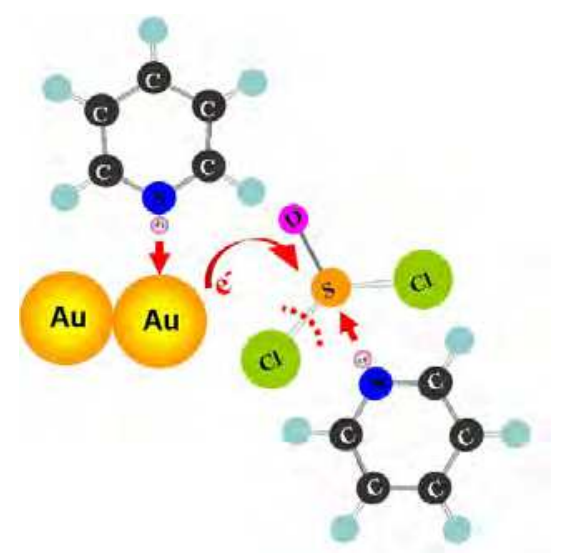

Fig. 13. A proposed oxidative dissolution mechanism for Au in OAR.

A more direct proof comes from the fact that the $\mathrm{Au}$ dissolution rate is distinctly reduced in the mixture of $\mathrm{SOCl}_{2}$ and fully deuterated py $\left(\mathrm{py}-d_{5}\right)$. The charge transfer interaction between $\mathrm{SOCl}_{2}$ and py- $d_{5}$ is evidenced in the Raman spectrum (Fig. 14); deuteration doesn't alter the chemical properties. However, due to the larger mass of py- $d_{5}$ than py, the surface adsorption and desorption of py- $d_{5}$ are thought to be slower than its undeuterated counterpart. 
It is noted that no known reduction products of $\mathrm{SOCl}_{2}$ such as sulfur have been confirmed so far. Therefore, the following possible reactions have been proposed:
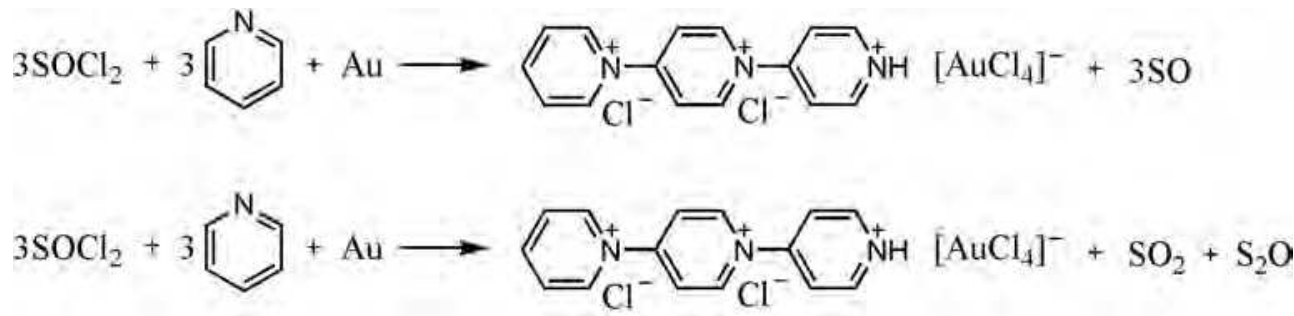

As for $\mathrm{Pt}$ and $\mathrm{Pd}$ in $\mathrm{OAR}$, the author believes their solubilities are related to surface passivation. It is well known in the research field of "corrosion science" that pure Pt and $\mathrm{Pd}$ are thermodynamically less noble than Au but, in reality, more noble than Au. The reason is that $\mathrm{Pt}$ and $\mathrm{Pd}$ surfaces passivate against oxidants over a wide range of $\mathrm{pH}$ values in aqueous solutions, while $\mathrm{Au}$ surface doesn't. This also explains why none of titanium, tantalum, chromium, and tungsten can be dissolved in OAR. The passivation prevents the ligand and the oxidant from accessing the metal atoms. To get clearer about the mechanism for the dissolution selectivity, electrochemical characterizations and simulations are needed.

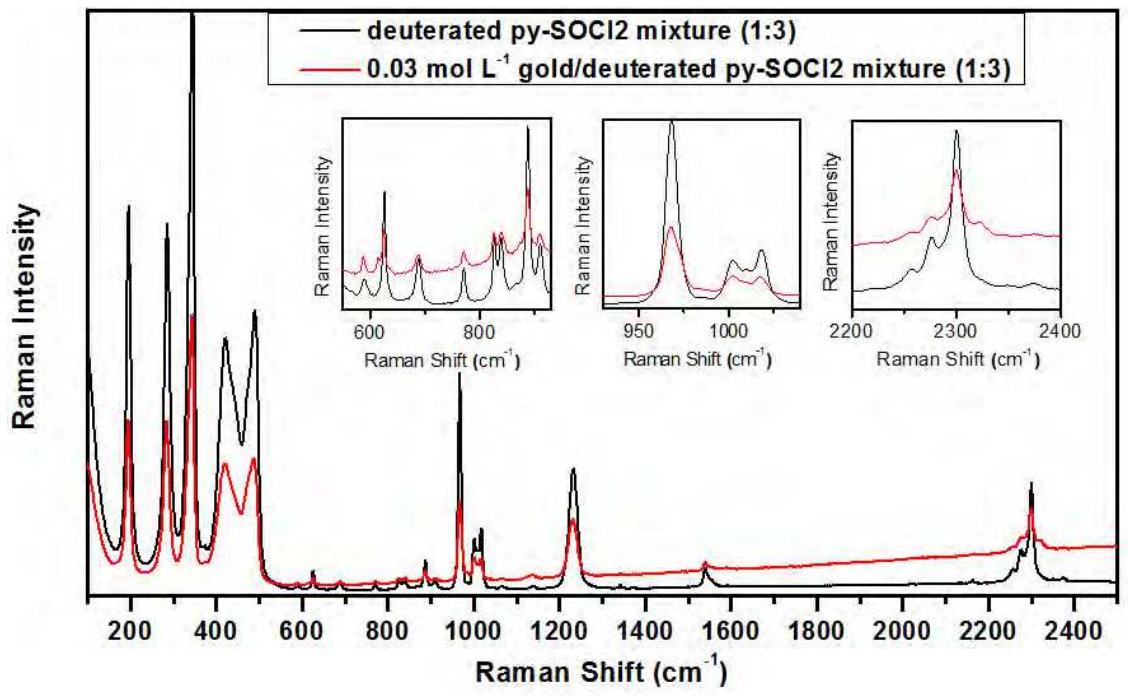

Fig. 14. Raman spectra of deuterated OAR and Au/OAR solution. The Raman shifts of the asymmetric and the symmetric Cl-S-Cl stretching are at 422 and $490 \mathrm{~cm}^{-1}$, respectively, indicating the charge-transfer interaction.

\section{Potential applications}

There are many potential applications of OAR in metallurgy, metal etching for integrated circuit fabrication in electronics, recovery of noble metals from catalysis industry, and synthesis of noble metal nano particles, etc. Two preliminary results are discussed here. 


\subsection{Recovery of Pt from bimetallic catalyst nanoparticles}

Bimetallic nanoparticles (NPs) of noble metal elements represent a new class of functional materials, and have been investigated intensively in the past fifteen years. Among the various combinations of bimetallic NPs, Au-Pt core-shell NPs (sometimes called Ptdecorated $\mathrm{Au}$ NPs, Pt-layered Au NPs, or Au-Pt dendritic hetero-aggregate NPs to account for the morphology of the the non-uniform and porous Pt shell) is an important category that has demonstrated improved catalytic activities (Zhou et al., 2006; Zhang et al., 2009; Lu et al., 2004; Wang et al., 2009). Recently, the author demonstrated an efficient leachingextraction process to recover Pt directly from $\mathrm{Pt}-\mathrm{Au}$ bimetallic nanoparticles using OAR (Lin, 2011). The purities of the $\mathrm{Pt}$ recovered from a mixture of $\mathrm{Au}$ and $\mathrm{Pt}$ nanoparticles, and from Pt-Au core-shell nanoparticle catalyst were as high as $99.49 \pm 0.22 \%$, and $95.02 \pm 0.08 \%$, respectively. The novel recovery process promises applications in catalysis industry. Here we show the example of leaching-extraction of $\mathrm{Pt}$ from $\mathrm{Pt}-\mathrm{Au}$ core-shell nanoparticle catalyst. Au core was formed by reducing $24 \mathrm{mg} \mathrm{HAuCl} \cdot 3 \mathrm{H}_{2} \mathrm{O}$ in $10 \mathrm{~mL}$ oleylamine at 120 ${ }^{\circ} \mathrm{C}$ for $3 \mathrm{~h}$ under an Ar blanket. $25 \mathrm{mg}$ platinum acetylacetonate was dissolved in $10 \mathrm{ml}$ oleylamine at $70{ }^{\circ} \mathrm{C}$, and then added into the dark purple Au colloidal solution at $120{ }^{\circ} \mathrm{C}$ under vigorous stirring. The solution was fast heated up to $235{ }^{\circ} \mathrm{C}$, and kept for $3 \mathrm{~h}$. The whole synthesis process was under Ar protection. The core-shell NPs were collected by precipitation with ethanol and centrifugation, and washed with mixtures of acetone and hexane. $10 \mathrm{mg}$ of the dark brown core-shell NPs were added into organic aqua regia composed of $\mathrm{SOCl}_{2}$ and py (3:1 in volume) at room temperature, and then diluted into 400 $\mathrm{mL} \mathrm{CH} \mathrm{CH}_{3} \mathrm{CN}$. The $\mathrm{CH}_{3} \mathrm{CN}$ solution was then mixed with $50 \mathrm{~mL}$ hexane under vigorous stirring. After the mixing, the mixture went through a fast phase separation at room temperature (Fig. 15). The dissolved $\mathrm{Au}$ went into the bottom $\mathrm{CH}_{3} \mathrm{CN}$ phase (yellow), and can be recovered simply by calcination (Fig. 16). Pt NPs were extracted out of the $\mathrm{CH}_{3} \mathrm{CN}$ solution, and re-dispersed in the upper hexane phase (brown). The Pt NPs can be recovered simply by evaporating the hexane.

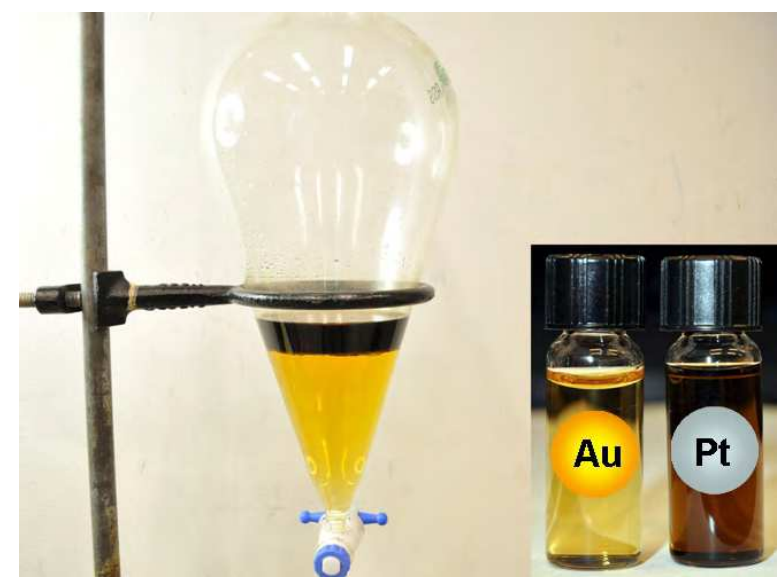

Fig. 15. A photograph showing the extraction result of Pt NPs from the dissolved Au after the leaching process: the bottom yellow phase is the $\mathrm{CH}_{3} \mathrm{CN}$ solution with dissolved $\mathrm{Au}$; the upper brown phase is the extracted Pt NPs dispersed in hexane. The two layers can be easily separated (inset). 


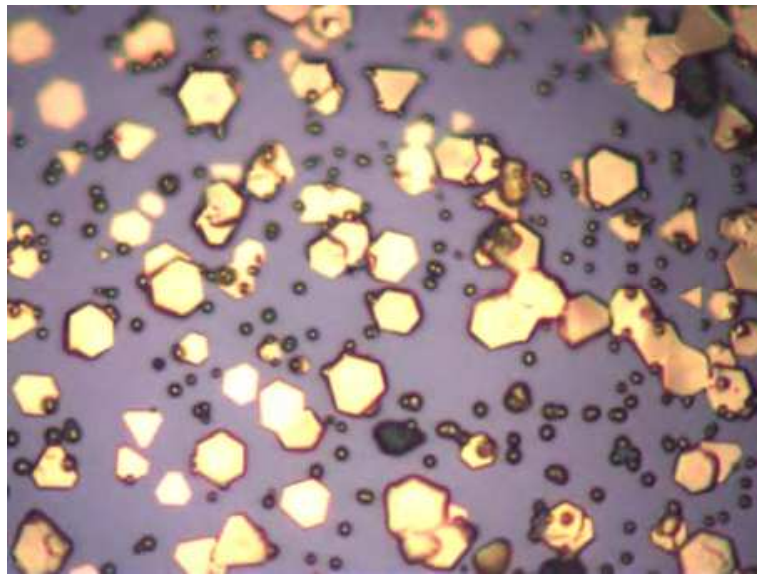

Fig. 16. An optical microscope image showing the recovered Au particles by calcinations.

\subsection{Fast etching of copper for applications in electronic industry}

Besides recovery of noble metals by OAR from waste electronic products/processing, etching of metals by OAR may find an important application in subtractive patterning of copper $(\mathrm{Cu})$ connection/conduction paths in electronic packaging. Various $\mathrm{Cu}$ etching processes have been developed for the fabrication of printed circuit board, and $\mathrm{Cu} / \mathrm{low}-\mathrm{K}$ interconnects associated with back-end-of-line (Bryce \& Berk, 1995; Cakir, 2006; Cakir et al., 2005; Halpern, 1953). However, the etching rates are still not satisfactory (Table 4); etchants of higher etching rates are desired. Recently, the author reported fast etching of $\mathrm{Cu}$ in $\mathrm{SOCl}_{2} / \mathrm{CH}_{3} \mathrm{CN}$ solutions (Lin \& Wong, 2011). The etching rate can be tuned over a wide range by varying the concentration of the etchant, and the stirring rate of the liquid. For example, the etching rate reaches $36 \mathrm{mg} \mathrm{min}^{-1} \mathrm{~cm}^{-2}$ in $1 \mathrm{~mol} \mathrm{~L}^{-1} \mathrm{SOCl}_{2} / \mathrm{CH}_{3} \mathrm{CN}$ under stirring

\begin{tabular}{|l|c|c|c|c|}
\hline \multicolumn{1}{|c|}{ Reference } & Etchant & $\begin{array}{c}\text { Concentration } \\
(\mathrm{mol} \mathrm{L}-1)\end{array}$ & $\begin{array}{c}\text { Temperature } \\
\left({ }^{\circ} \mathrm{C}\right)\end{array}$ & $\begin{array}{c}\text { Etching rate } \\
\left(\mathrm{mg} \mathrm{min}^{-1} \mathrm{~cm}^{-2}\right)\end{array}$ \\
\hline Cakir et al., 2005 & $\mathrm{FeCl}_{3}$ & 3.76 & 50 & 3.5 \\
\hline Cakir et al., 2005 & $\mathrm{CuCl}_{2}$ & 2.33 & 50 & 1.7 \\
\hline Halpern, 1953 & $\mathrm{FeCl}_{3}$ & 2 & 50 & 27 \\
\hline Halpern, 1953 & $\mathrm{FeCl}_{3}$ & 2 & 30 & 17 \\
\hline Bryce \& Berk, 1995 & $\mathrm{O}_{2} / \mathrm{NH}_{3} \cdot \mathrm{H}_{2} \mathrm{O}$ & 0.9 atm/0.74 & 26 & 0.03 \\
\hline Cakire, 2006 & $\mathrm{Alkaline}$ & $\mathrm{N} / \mathrm{A}$ & $30-60$ & $13-27$ \\
\hline Cakire, 2006 & $\mathrm{CuCl}_{2}$ & $>2$ & $50-54$ & $11-22$ \\
\hline Cakire, 2006 & $\mathrm{FeCl}_{3}$ & $>2$ & $43-49$ & $11-22$ \\
\hline Lin \& Wong, 2011 & $\mathrm{SOCl}_{2} / \mathrm{CH}_{3} \mathrm{CN}$ & 1 & 20 & 36 \\
\hline Lin \& Wong, 2011 & $\mathrm{SOCl}_{2} / \mathrm{CH}_{3} \mathrm{CN}$ & 2 & 20 & 53 \\
\hline Lin \& Wong, 2011 & $\mathrm{SOCl}_{2} / \mathrm{CH}_{3} \mathrm{CN}$ & 1 & 20 & 320 \\
\hline Lin \& Wong, 2011 & $\mathrm{FeCl}_{3}$ & 2 & 50 & 19 \\
\hline
\end{tabular}

Table 4. A brief comparison of etchants for $\mathrm{Cu}$. 
at room temperature, which is much faster than any currently used etchant for $\mathrm{Cu}$. With the assistance of sonication, the etching rate reaches $320 \mathrm{mg} \mathrm{min}^{-1} \mathrm{~cm}^{-2}$. The reactions involved are shown below. Based on the selectivity of OAR, $\mathrm{Au}$ and $\mathrm{Pt}$ are used as the effective masks on $\mathrm{Cu}$ and $\mathrm{Au}$, respectively, for the subtractive patterning of $\mathrm{Cu}$ and $\mathrm{Au}$ conduction paths. Preliminary studies showed acceptable and controllable undercuts of the etched conduction paths by the OAR.

$$
\begin{array}{ll} 
& 6 \mathrm{Cu}+2 \mathrm{SOCl}_{2} \rightarrow \mathrm{Cu}_{2} \mathrm{~S}+4 \mathrm{CuCl}+\mathrm{SO}_{2} \\
& 4 \mathrm{CuCl}+2 \mathrm{SOCl}_{2} \rightarrow 4 \mathrm{CuCl}_{2}+\mathrm{S}+\mathrm{SO}_{2} \\
& \mathrm{Cu}_{2} \mathrm{~S}+2 \mathrm{SOCl}_{2} \rightarrow 2 \mathrm{CuCl}_{2}+2 \mathrm{~S}+\mathrm{SO}_{2} \\
\text { Overall reaction: } & 2 \mathrm{Cu}+2 \mathrm{SOCl}_{2} \rightarrow 2 \mathrm{CuCl}_{2}+\mathrm{S}+\mathrm{SO}_{2}
\end{array}
$$

\section{Acknowledgment}

The author acknowledges Prof. C. P. Wong for financial support of part of the research work.

\section{References}

Awadalla, F. T.; Molnar, R. E.; \& Riteey, G. M. (1992). Recovery of Platinum Group Metals (PGM) from Acidic Solutions by Reduction Precipitation with Sodium Borohydride. US Patent, 5,304,233

Bovio, B.; Burini, A. \& Pietroni, B. R. (1993). Reactions of Trimeric 1-benzyl-2-gold(I) imidazole Leading to $\mathrm{Au}(\mathrm{I})$ Carbene Complexes - Crystal-Structure of [1-benzyl-3benzoyl-imidazolin-2-yliden] chloro Gold(I). Journal of Organometallic Chemistry, Vol.452, pp. 287-291

Bryce, C. \& Berk, D. (1995). Kinetics of the Dissolution of Copper in Iron(III) Chloride Solutions. Industrial \& Engineering Chemistry Research, Vol.34, pp. 1412-1418

Cade, J. A. \& Gerrard, W. (1953). Action of Thionyl Chloride on Carboxylic Acids in Presence of Pyridine. Nature, Vol.172, pp. 29

Cakir, O.; Temel, H. \& Kiyak, M. (2005). Chemical Etching of Cu-ETP Copper. Journal of Materials Processing Technology, Vol.162, pp. 275-279

Cakir, O. (2006). Copper Etching with Cupric Chloride and Regeneration of Waste Etchant. Journal of Materials Processing Technology, Vol.175, pp. 63-68

Cau, L.; Deplano, P.; Marchio, L.; Mercuri, M. L.; Pilia, L.; Serpe, A. \& Trogu, E. F. (2003). New Powerful Reagents Based on Dihalogen/N,N '-dimethylperhydrodiazepine2,3-dithione Adducts for Gold Dissolution: the IBr Case. Dalton Transactions, Vol.10, pp. 969-1974

Edwards, R. I. \& Nattrass, M. J. (1978). Separation and Purification of Platinum and Palladium. US Patent, 4,105,742

Garcia, E. E.; Greco, C. V. \& Hunsberger, I. M. (1960). Facile Bromination of Pyridine-Type Heterocycles at the Beta-position. Journal of the American Chemical Society, Vol.82, pp. $4430-4431$ 
Geary, W. J. (1971). The Use of Conductivity Measurements in Organic Solvents for the Characterization of Coordination Compounds. Coordination Chemistry Reviews Vol.7, pp. 81-122

Gerrard, W. \& Thrush, A. M. (1953). Reactions in Carboxylic Acid Thionyl Chloride Systems. Journal of the Chemical Society, Vol., pp. 2117-2120

Halpern, J. (1953). Kinetics of the Dissolution of Copper in Aqueous Ammonia. Journal of the Electrochemical Society, Vol.100, pp. 421-428

Harkness, A. C. \& Daggett Jr., H. M. (1965). The Electrical Conductivities of Some Tetra-nalkylammonium Salts in Acetonitrile. Canadian Journal of Chemistry, Vol.43, pp. 1215-1221

Higashi, F.; Mashimo, T. \& Takahashi, I. (1986). Preparation of Aromatic Polyesters by Direct Polycondensation with Thionyl Chloride Pyridine. Journal of Polymer Science Part a-Polymer Chemistry, Vol.24, pp. 97-102

Human, J. P. E. \& Mills, J. A. (1946). Action of Thionyl Chloride on Carboxylic Acids in Presence of Pyridine. Nature, Vol.158, pp. 877

Korshak, V. V.; Vinograd, Sv. \& Pankrato, Va. (1971). New Ways to Synthesize Polybenzimidazoles and Polybenzoxazoles. Vysokomolekulyarnye Soedineniya Section $B$, Vol.13, pp. 550-551

Lakewood, J. B. \& Arvada, C. (1977). Separation and Selective Recovery of Platinum and Palladium by Solvent Extraction. US Patent, 4,041,126

Lin, W.; Xiu, Y. H.; Jiang, H. J.; Zhang, R. W.; Hildreth, O.; Moon, K. S. \& Wong, C. P. (2008). Self-Assembled Monolayer-Assisted Chemical Transfer of In Situ Functionalized Carbon Nanotubes. Journal of the American Chemical Society, Vol.130, pp. 9636-9637

Lin, W.; Zhang, R. W.; Jang, S. S.; Wong, C. P. \& Hong , J. I. (2010). "Organic Aqua Regia"Powerful Liquids for Dissolving Noble Metals. Angewandte Chemie-International Edition, Vol.49, pp. 7929-7932

Lin, W. (2011). Recovery of High-purity Pt from Pt-Au Bimetallic Nanoparticles Using Organic Aqua Regia. Rare Metals, accepted

Lin, W. \& Wong, C. P. (2011). Fast Etching of Copper in Thionyl Chloride/Acetonitrile Solutions. Corrosion Science, Vol. 53, pp. 3055-3057

Lu L. H.; Sun, G. Y.; Zhsng, H. J.; Wang, H. S.; Xi, S. Q.; Hu, J. Q.; Tian, Z. Q. \& Chen, R. (2004). Fabrication of Core-Shell Au-Pt Nanoparticle Film and Its Potential Application as Catalysis and SERS Substrate. Journal of Materials Chemistry, Vol.14, pp. 1005-1009

Mortier, T.; Persoons, A. \& Verbiest, T. (2005). Oxidation of Solid Gold in Chloroform Solutions of Cetyltrimethylammonium Bromide. Inorganic Chemistry Communications, Vol.8, pp. 1075-1077

Nakao, Y. (1992). Dissolution of Noble Metals in Halogen Halide Polar Organic Solvent Systems. Journal of the Chemical Society-Chemical Communications, Vol.5, pp. 426-427

NatureEditorial (2010). Dissolving Precious Metals. Nature, Vol.467, pp. 503

Qi, P. H. \& Hiskey, J. B. (1991). Dissolution Kinetics of Gold in Iodide Solutions. Hydrometallurgy, Vol.27, pp. 47-62

Raisanen, M. T.; Kemell, M.; Leskela, M. \& Repo, T. (2007). Oxidation of Elemental Aold in Alcohol Solutions. Inorganic Chemistry, Vol.46, pp. 3251-3256 
Ricca, G. \& Severini, F. (1988). C-13 and H-1-NMR Study of the Pyridine-initiated Oligomerization of Maleic-anhydride and of the Polymer Structure. Polymer, Vol.29, pp. 880-882

Ritter S. K. A New Twist on Aqua Regia, In: CEEN, March 31, 2011, Available from: http://pubs.acs.org/cen/news/89/i14/8914notw4.html

Schenk, P. W. \& Steudel, R. (1963). Addukte Des Dischwefelmonoxyds. Angewandte Chemie, Vol.75, pp. 793

Schmidbaur, H.; \& Jandik, P. (1983). Au(I)-Au(II) AND Au(I)-Au(III) Oxidation in Ylide Complexes with Chlorinating Agents. Inorganica Chimica Acta-Articles, Vol.74, pp. 97-99

Senanayake, G. (2008). A Review of Effects of Silver, Lead, Sulfide and Carbonaceous Matter on Gold Cyanidation and Mechanistic Interpretation. Hydrometallurgy, Vol.90, pp. 46-73

Steudel, R. \& Steudel, Y. (2007). Charge-Transfer Complexes between the Sulfur Molecules SO2, S2O, S-3, SONH, and SOCl2 and the Amine Donors NH3 and NMe3 - A Theoretical Study. European Journal of Inorganic Chemistry, Vol.27, pp. 4385-4392

Urquhart, J. Challenging Aqua Regia's Throne, In: Chemistry World, September 23, 2010, Available from:

<http://www.rsc.org/chemistryworld/News/2010/September/23091001.asp>

Vulakh, E. L.; Freidlin, E. G. \& Gitis, S. S. (1975). Reaction of Substituted Benzoic Acids with Thionyl Chloride. Zhurnal Organicheskoi Khimii, Vol.11, pp. 1481-1486

Wang, S. Y.; Kristian, N.; Jiang, S. P. \& Wang, X. (2009). Controlled Synthesis of Dendritic $\mathrm{Au} @ \mathrm{Pt}$ Core-Shell Nanomaterials for Use as An Effective Fuel Cell Electrocatalyst. Nanotechnology, Vol.20.

Yeston, J. (2010). Golden Selection. Science, Vol.330, pp. 153

Zhang, W.; Li, L.; Du, Y. K.; Wang, X. M. \& Yang, P. (2009). Gold/Platinum Bimetallic Core/Shell Nanoparticles Stabilized by a Fr,chet-Type Dendrimer: Preparation and Catalytic Hydrogenations of Phenylaldehydes and Nitrobenzenes. Catalysis Letters, Vol.127, pp. 429-436

Zhou, S. G.; Mcllwrath, K.; Jackson, G. \& Eichhorn, B. (2006). Enhanced CO Tolerance for Hydrogen Activation in Au-Pt Dendritic Heteroaggregate Nanostructures. Journal of the American Chemical Society, Vol.128, pp. 1780-1781

Zuffanti, S. (1948). Preparation of acyl chlorides with thionyl chloride. Journal of Chemical Education, Vol.25, pp. 481 


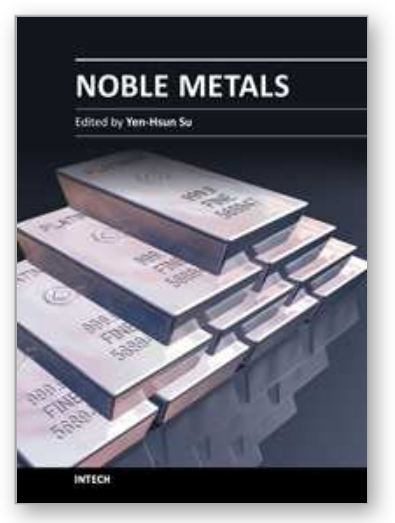

\author{
Noble Metals \\ Edited by Dr. Yen-Hsun Su
}

ISBN 978-953-307-898-4

Hard cover, 426 pages

Publisher InTech

Published online 01, February, 2012

Published in print edition February, 2012

This book provides a broad spectrum of insights into the optical principle, resource, fabrication, nanoscience, and nanotechnology of noble metal. It also looks at the advanced implementation of noble metal in the field of nanoscale materials, catalysts and biosystem. This book is ideal not only for scientific researchers but also as a reference for professionals in material science, engineering, nonascience and plasmonics.

\title{
How to reference
}

In order to correctly reference this scholarly work, feel free to copy and paste the following:

Wei Lin (2012). Organic Aqua Regia: Discovery, Fundamentals, and Potential Applications, Noble Metals, Dr. Yen-Hsun Su (Ed.), ISBN: 978-953-307-898-4, InTech, Available from:

http://www.intechopen.com/books/noble-metals/organic-aqua-regia-discovery-fundamentals-and-potentialapplications

\section{INTECH}

open science | open minds

\author{
InTech Europe \\ University Campus STeP Ri \\ Slavka Krautzeka 83/A \\ 51000 Rijeka, Croatia \\ Phone: +385 (51) 770447 \\ Fax: +385 (51) 686166 \\ www.intechopen.com
}

\author{
InTech China \\ Unit 405, Office Block, Hotel Equatorial Shanghai \\ No.65, Yan An Road (West), Shanghai, 200040, China \\ 中国上海市延安西路65号上海国际贵都大饭店办公楼405单元 \\ Phone: +86-21-62489820 \\ Fax: $+86-21-62489821$
}


(C) 2012 The Author(s). Licensee IntechOpen. This is an open access article distributed under the terms of the Creative Commons Attribution 3.0 License, which permits unrestricted use, distribution, and reproduction in any medium, provided the original work is properly cited. 